\title{
Luteoma Recorrente da Gravidez com Virilização Materna e Fetal
}

\author{
Recurrent Luteoma of Pregnancy with Maternal \\ and Fetal Virilization
}

Amadeu Ramos da Silva Filho, Raquel Tavares Boy Silva

\begin{abstract}
RESUMO
Os luteomas da gravidez são pseudotumores ovarianos diagnosticados pelo exame ultrasonográfico ou durante realização de cesariana e laqueadura pós-parto. Determinam, na segunda metade da prenhez, sinais de virilização materna em um quarto dos casos, o mesmo ocorrendo com a metade dos fetos femininos destas gestantes virilizadas nos quais se observa hipertrofia clitoridiana ou fusão labial. As dosagens séricas maternas dos hormônios androgênicos durante a prenhez e do sangue umbilical por ocasião do parto revelam taxas significativamente aumentadas. No exame ultra-sonográfico apresentam-se como estruturas sólidas ou cístico-sólidas, que após o parto tendem a regredir com o ovário readquirindo as dimensões normais em poucas semanas. Os autores apresentam uma paciente que em duas gestações sucessivas apresentou virilização materna e fetal. Ao exame ultra-sonográfico foram evidenciadas imagem ovariana nodular e dosagens elevadas dos androgênios plasmáticos.
\end{abstract}

PALAVRAS-CHAVE: Hiperandrogenismo. Genitália ambigua. Ovário: pseudotumores. Massas anexiais.

\section{Introdução}

Os luteomas da gravidez são pseudotumores ovarianos descritos pela primeira vez por Sternberg em $1963^{1}$. Parece tratar-se de uma resposta exagerada, por motivos ainda desconhecidos, do estroma ovariano aos hormônios da gravidez ${ }^{2-5}$.

A maior parte das pacientes é assintomática, sendo a lesão ovariana diagnosticada por exame ultra-sonográfico ou por ocasião de cirurgias como a cesariana ou laqueadura pós-parto. Ocorrem bilateralmente em 30\% dos casos $^{2}$ e em $25 \%$ das vezes, principalmente na segunda metade da prenhez, as pacientes apresentam sinais de virilização representada por acne, sobretudo no ros-

Hospital Universitário Pedro Ernesto

Departamento de Saúde Materno e Infantil e Departamento de Biologia Celular e Genética da Universidade do Estado do Rio de Janeiro

Correspondência:

Amadeu Ramos da Silva Filho

Rua: Ministro Corrêa de Melo, 113 apto 802 - Leblon

22430-110 - Rio de Janeiro - RJ

Fone: (21) 512-7274

Fone/fax: (21) 576-9896 to, face anterior do tórax e região dorsal, assim como crescimento exagerado de pêlos com distribuição andróide, clitorimegalia e tonalidade vocal mais grave. $O$ perfil dessas mulheres indica prevalência na faixa etária entre 30 a 40 anos, pretas e multiparas ${ }^{2}$. Em torno de 50 a $60 \%$ de fetos femininos nascidos de mães virilizadas apresentam sinais de virilização, representados por hipertrofia clitoridiana ou fusão labial. Embora mais de 100 casos de luteomas em gravidez tenham sido descritos na literatura ${ }^{2}$, poucos casos de recorrência têm sido relatados ${ }^{2,6}$ e é excepcional a repetição do quadro de virilização materna e/ou fetal. ${ }^{2}$

Os autores apresentam o caso de uma paciente que, em duas gestações subseqüentes e separadas por intervalo de quatorze meses, apresentou a excepcional recorrência de luteoma da gravidez com virilização materna e fetal.

\section{Relato do caso}

Primeira gravidez: mulher branca de 17 anos 
de idade, grávida pela primeira vez, apresentou a partir do sexto mês de gestação aumento da pilificação e acne na face (Figura 1), tórax e abdome. No mesmo período notou que sua voz havia adquirido tonalidade mais grave. A partir do sétimo mês percebeu aumento volumétrico do clitóris (Figura 2). Não foram feitas outras investigações e o único exame ultra-sonográfico realizado não evidenciava imagem ovariana tumoral. Teve parto vaginal de início espontâneo na trigésima sétima semana. O concepto pesava 2.940 gramas e apresentava genitália externa ambígua, observando-se imagem fálica e fusão labial (Figura 3). Com sessenta dias de pós-parto evidenciou-se à ultrasonografia com Doppler imagem no ovário esquerdo que se apresentava como uma formação nodular sólida medindo $5 \mathrm{~cm}$ no seu maior diâmetro, com vasos de baixa resistência (Figura 4). Após seis meses do parto a mãe apresentava ciclos menstruais regulares, diminuição do hirsutismo, desaparecimento da acne e pequena regressão do volume clitoridiano. Aos seis meses de idade, com o sexo feminino estabelecido, a infante foi submetida à plástica genital com redução da hipertrofia clitoridiana.

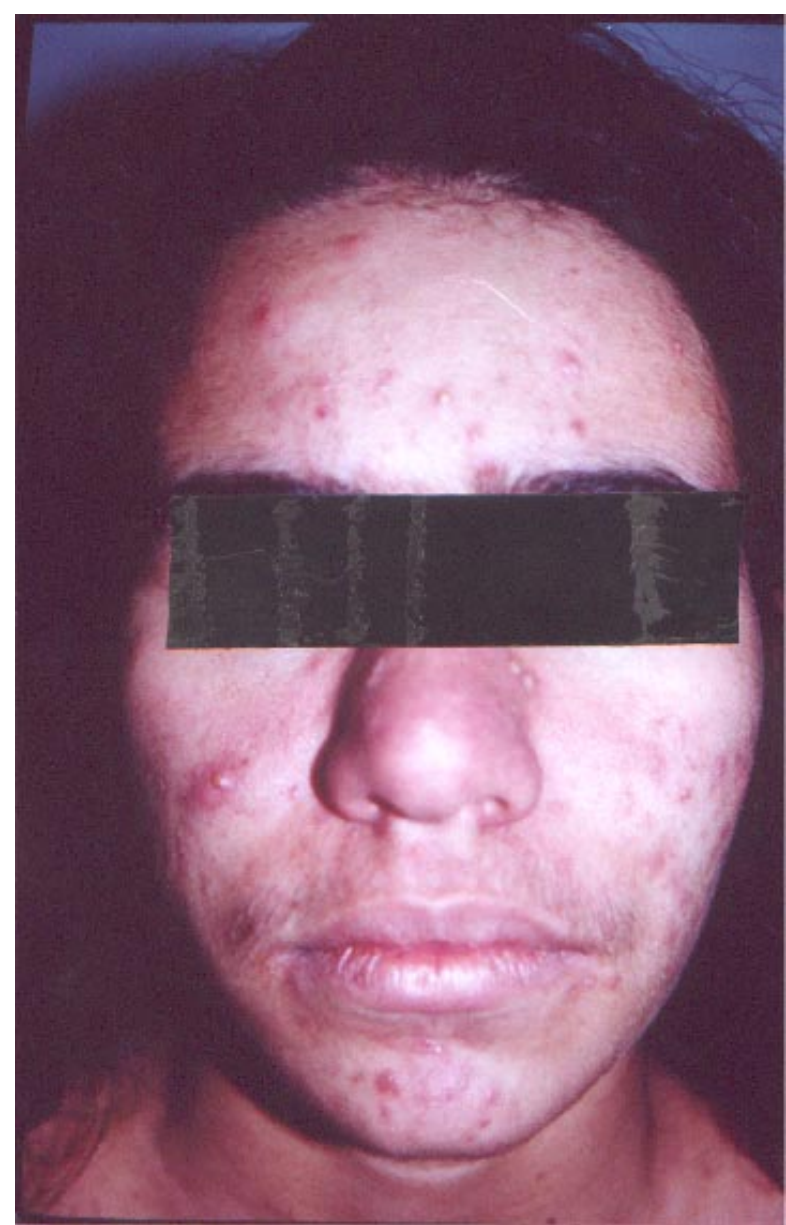

Figura 1 - Face da paciente apresentando aumento da pilificação e acne intensa

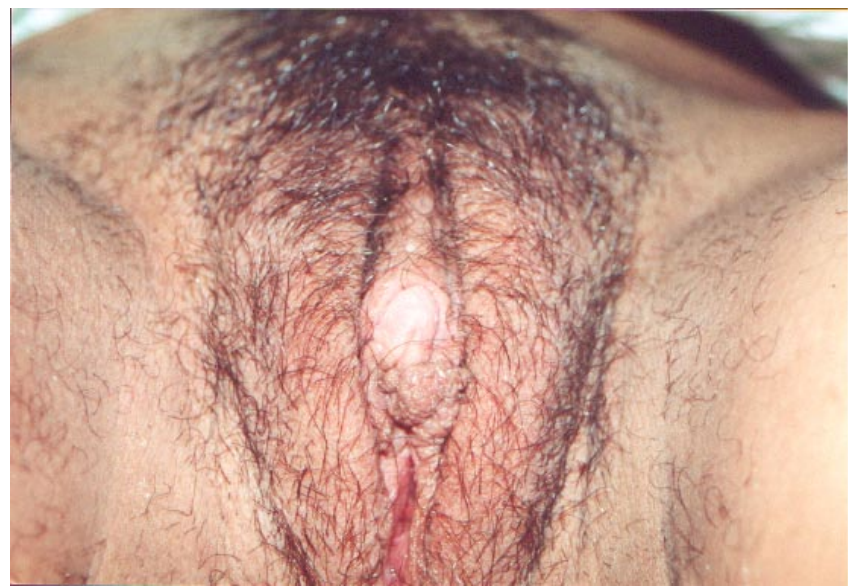

Figura 2 - Genitália externa da grávida apresentando hipertrofia do clitóris e distribuição pilosa do tipo andróide.

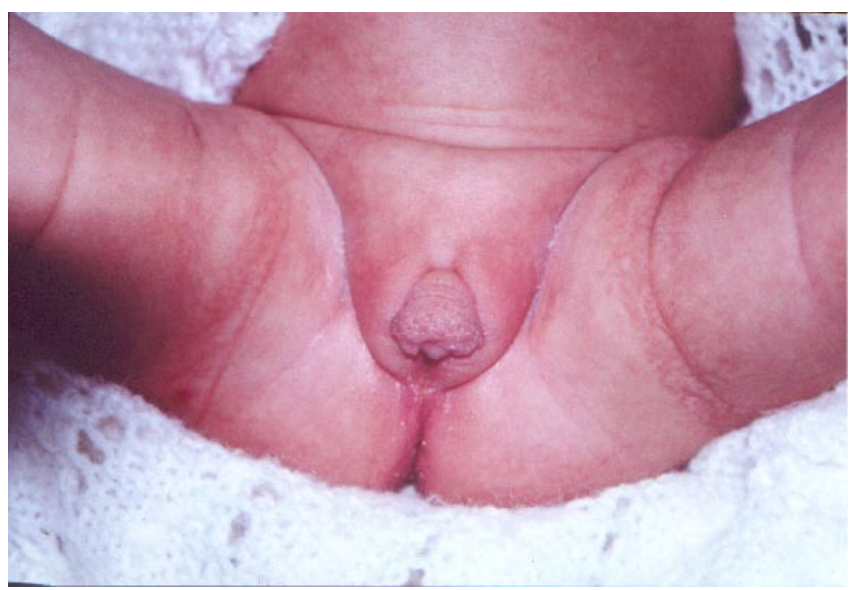

Figura 3 - Genitália externa do recém-nato com importante hipertrofia do clitóris e fusão labial.

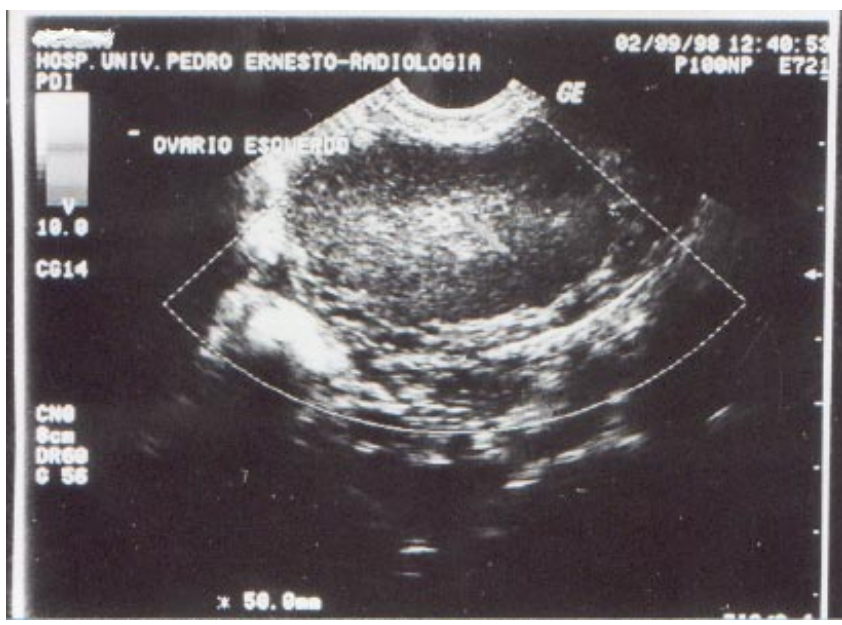

Figura 4 - Imagem ultra-sonográfica com dopplervelocimetria do ovário esquerdo sessenta dias após o primeiro parto. Observa-se formação nodular sólida medindo $5 \mathrm{~cm}$ no seu maior diâmetro, apresentando vasos de baixa resistência.

Segunda gravidez: Iniciou o pré-natal no Hospital da Universidade Estadual do Rio de Janeiro com dezenove semanas de gestação e 
dezessete meses após o parto anterior. Apresentava recorrência das manifestações virilizantes: acne, hirsutismo, aumento do clitóris e timbre vocal mais grave. Uma ultra-sonografia realizada na $24^{\text {a }}$ semana mostrava ovário esquerdo aumentado apresentando imagem tumoral sólida de paredes espessadas com textura ecogênica heterogênea e medindo $46 \mathrm{~mm}$ no seu maior diâmetro (Figura 5); ovário direito sem anormalidades. As dosagens dos androgênios na $26^{a}$ semana gestacional revelavam no soro materno: testosterona total $=45.301 \mathrm{pg} / \mathrm{mL}(\mathrm{VR}: 650-1.119 \mathrm{pg} / \mathrm{mL})$; testosterona livre $=74,3 \mathrm{pg} / \mathrm{mL}$ (VR: $0,7-3,6 \mathrm{pg} /$ $\mathrm{mL}$ ); androstenediona $=18.647 \mathrm{pg} / \mathrm{ml}$ (VR: 650$3.000 \mathrm{pg} / \mathrm{ml}$ ); sulfato de deidroepiandrosterona = $1,90 \mu \mathrm{g} / \mathrm{mL}$ (VR: 0,35-4,3 $\mu \mathrm{g} / \mathrm{mL}$ ). Na 34 ${ }^{\mathrm{a}}$ semana a imagem do nódulo ovariano esquerdo apresentava as mesmas características, medindo $68 \mathrm{~mm}$ no maior diâmetro. $\mathrm{Na} 37^{\mathrm{a}}$ semana entrou em trabalho de parto espontâneo, dando à luz um recémnato do sexo masculino em boas condições de vitalidade, pesando 3.160 gramas e sem anormalidades morfológicas. As dosagens dos androgênios séricos da paciente no dia do trabalho de parto mostravam: testosterona total: $22.522 \mathrm{pg} / \mathrm{mL}$; testosterona livre: $25,9 \mathrm{pg} / \mathrm{mL}$; androstenediona: $21.494 \mathrm{pg} / \mathrm{mL}$. As dosagens dos androgênios do sangue do cordão umbilical por ocasião do nascimento mostraram: testosterona total: $5.245 \mathrm{pg} / \mathrm{mL}$; testosterona livre: $11,5 \mathrm{pg} / \mathrm{mL}$; androstenediona: $15.524 \mathrm{pg} / \mathrm{mL}$. Na quarta semana após o parto apresentava piora da acne facial e torácica, hirsutismo mantido e timbre vocal grave semelhante ao observado no final da gravidez, o exame ultrasonográfico demonstrava no ovário esquerdo formação nodular, apresentando calcificação no seu interior, medindo $34 \mathrm{~mm}$ no seu diâmetro máximo. As dosagens revelavam: testosterona total = $506 \mathrm{pg} / \mathrm{mL}$; testosterona livre: $2,8 \mathrm{pg} / \mathrm{mL}$; androstenediona: $3.432 \mathrm{pg} / \mathrm{mL}$; sulfato de desidroepiandrosterona: $2,2 \mu \mathrm{g} / \mathrm{mL}$. Na $10^{\text {a }}$ décima semana após o parto apresentava melhora da acne facial e torácica, diminuição do crescimento piloso e discreta redução do volume clitoridiano; tonalidade vocal inalterada. A ultra-sonografia demonstrava a imagem tumoral do ovário esquerdo apresentando as mesmas dimensões e características do exame anterior (Figura 6). As dosagens dos andrógenos séricos da paciente revelavam: testosterona total: $210 \mathrm{pg} / \mathrm{mL}$; testosterona livre: $1.0 \mathrm{pg} / \mathrm{mL}$; androstenediona: $2.944 \mathrm{pg} / \mathrm{mL}$; sulfato de desidroepiandrosterona: $2.10 \mu \mathrm{g} / \mathrm{mL}$. Em 5 de janeiro de 2001, 17 semanas após o parto, apresentava-se sem acne, pêlos com características normais, timbre vocal menos grave, volume clitoridiano semelhante à ultima consulta. A ultra-sonografia evidenciava a formação nodular do ovário esquerdo com calcificação no seu interior e medindo $30 \mathrm{~mm}$ no maior diâmetro. Durante a lactação prescrevemos o uso de 0,030 $\mathrm{mg}$ de levonorgestrel como método contraceptivo. Terminada a amamentação substituímos pela associação que contém $2 \mathrm{mg}$ de acetato de ciproterona e $0,035 \mathrm{mg} \mathrm{de}$ etinilestradiol.

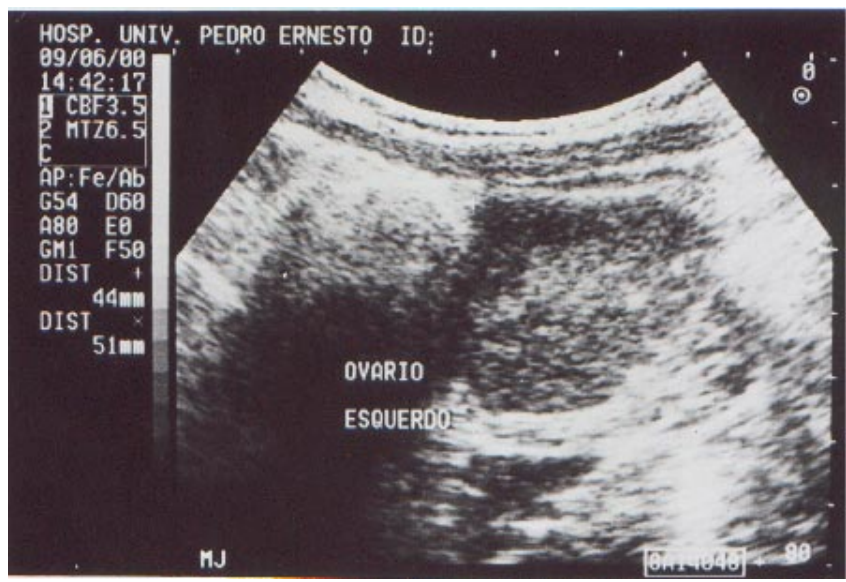

Figura 5 - Imagem ultra-sonográfica na $24^{a}$ semana da segunda gravidez. Ovário esquerdo exibindo imagem tumoral sólida com $4,6 \mathrm{~cm}$ no seu maior diâmetro com paredes espessadas e textura ecogênica heterogênea.

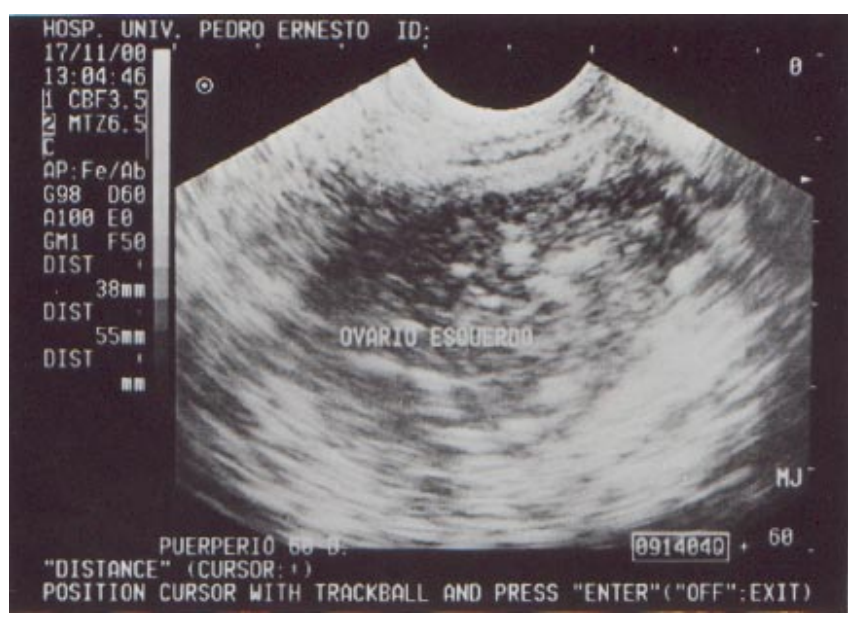

Figura 6 - Imagem ultra-sonográfica do ovário esquerdo na $10^{2}$ semana após o segundo parto. Observa-se nódulo sólido com textura ecogênica heterogênea.

\section{Discussão}

Os luteomas gravídicos podem ser microscópicos ou em raros casos atingir até $20 \mathrm{~cm}$ no seu maior diâmetro, mas apresentam diâmetro médio de $6,6 \mathrm{~cm}^{6}$. São tumores sólidos, bem delimitados, demonstram freqüentemente focos hemorrágicos, o que determina sua cor avermelhada tendendo ao marrom ${ }^{7}$. Podem ser únicos ou na metade das vezes múltiplos. Micros- 
copicamente evidencia-se hiperplasia reacional do estroma com luteinização, característica muito incomum em patologia tumoral ${ }^{8}$. No exame ultra-sonográfico apresentam-se bem identificados como massas de ecogenicidade complexa, por vezes como estruturas sólidas ou cístico-sólidas. Logo após o parto, cessada a estimulação gestacional, tendem a regredir, o que permite ao ovário atingir o seu tamanho normal em algumas semanas ${ }^{9}$.

Durante o período gravídico fisiológico ocorre um aumento da concentração sérica de androgênios. No primeiro trimestre eleva-se a concentração da testosterona total, provavelmente pela maior produção hepática de testosteronebinding globulin (TBG) estimulada pelas maiores concentrações de estrogênios. No último trimestre observa-se pico de concentração da testosterona livre e androstenediona. A glândula supra-renal parece contribuir para o aumento da concentração basal de andrógenos. Embora a secreção adrenal do sulfato de deidroepiandrosterona (SDHEA) possa dobrar a sua concentração prégravídica, sua concentração no soro materno diminui pela ação da $16 \alpha$-hidroxilação no figado e pela conversão para estradiol na placenta ${ }^{3}$.

Apesar da maior produção de andrógenos durante a gravidez normal, as mulheres estão protegidas da virilização por diversos mecanismos compensatórios, como maior produção de proteína carreadora neutralizante e altas concentrações de progesterona ligando-se aos receptores androgênicos. Adicionalmente, a aromatização placentária, transformando androgênios em estrogênios, protege o feto de virilização. Apesar disso, observam-se no sangue umbilical de fetos não virilizados, cujas mães apresentam manifestações de virilização, altas concentrações de andrógenos o que faz supor também a existência neles de mecanismos protetores ${ }^{3}$. Todos os luteomas da gravidez são ativos ${ }^{7}$, e a existência de virilização materna associada ou não à fetal, ocorre quando os mecanismos anteriormente descritos, por alguma razão, não estão presentes.

A virilização materna durante a gestação é um fenômeno raro e, na maioria das vezes, a elevada produção de androgênios origina-se dos ovários. As causas mais comuns estão representadas pelo luteoma gravídico e pelos grandes cistos teca-luteínicos designados hyperreactio luteinalis ${ }^{2,9,10}$.

O hiperreactio luteinalis geralmente é bilateral, constituindo-se de grandes cistos. Não causam virilização fetal e costumam regredir no período do pós-parto. Estão associados a altas concentrações do hormônio gonadotrófico coriônico como na gestação múltipla, neoplasia trofoblástica gestacional, eritroblastose fetal e diabete melito.

Excepcionalmente, outras patologias podem produzir hiperandrogenismo durante a gravide $z^{2}$ e entre elas se incluem: tumores da granulosa, tumor das células de Sertoli-Leydig, luteomas estromais ou tumores de células lipóides, síndrome dos ovários policísticos ${ }^{9}$, tumores adrenais, tumores do cordão sexual e o tumor de Krukenberg.

Um raro caso ${ }^{11}$ apresentou-se duas semanas após o parto, em mulher anteriormente assintomática, com manifestações de acne facial, abdome distendido, massa anexial direita complexa com ascite. A radiografia do tórax evidenciava pequeno derrame pleural à direita e a dosagem do CA 125 encontrava-se elevada. Indicada laparotomia com ooforectomia direita, por suspeita de malignidade ovariana, a histopatologia evidenciou tratar-se de um luteoma gravídico. Portanto, em gestantes ou puérperas com estas manifestações clínicas, o luteoma deve ser incluído no diagnóstico diferencial.

O encontro de formação tumoral sólida ou cístico-sólida associada ao quadro de hiperandrogenismo materno não é, por si só, indicação de cesariana e muito menos de ooforectomia. Esta interessante patologia ovariana, além de afetar mulheres jovens, apresenta em poucas semanas regressão total das manifestações de hiperandrogenismo, a imagem ovariana complexa ao ultrasom diminui suas dimensões, embora possa permanecer visivel por meses. A lactação e o retorno das menstruações ocorrem dentro do período fisiológico.

Quando a cesariana é realizada por indicação obstétrica, o inventário ovariano avaliará a possibilidade de realizar-se a biópsia por incisão ou, nos casos de lesão bem delimitada, por excisão, mas sempre conservando a gônada ${ }^{12,13}$.

No caso por nós apresentado, além da anticoncepção hormonal já descrita, estamos monitorando a cada três meses as manifestações clínicas de hiperandrogenismo e, por imagem ultra-sonográfica, o ovário comprometido. Não existe por parte da paciente desejo de nova gestação, o que facilita a conduta conservadora adotada.

\section{SUMMARY}

Luteomas of pregnancy are ovarian pseudotumors diagnosed by ultrasound, during cesarean section or at postdelivery tubal ligation. Twenty-five per cent of the cases appear around the second half of pregnancy. Usually there are signs of maternal virilization and $50 \%$ are detected because female 
newborns show clitorimegaly and/or labial fusion. The concentrations of androgenic steroids in the maternal blood during pregnancy and in the cord blood at child-birth show significantly increased rates. The ultrasound shows solid or cystic-solid structures and few weeks after the delivery they decrease and the ovary size returns to normal. The authors report a case of a patient who exhibited virilization signs in two consecutive pregnancies as well as in the two female fetuses. At adnexal sonographic examination a solid tumoral image was found in both pregnancies. Serum androgen levels were increased.

KEY WORDS: Hyperandrogenism in pregnancy. Genital ambiguity. Ovary: pseudotumors. Adnexal masses.

\section{Referências}

1. Sternberg WH. Nonfunctioning ovarian neoplasms. In: Grady HG, Smith DE, editors. The Ovary. $1^{\text {st }}$ ed. Baltimore:Williams \& Wilkins; 1963. p.20954.

2. Manganiello PD, Adams LV, Harris RD, Ornvold K. Virilization during pregnancy with spontaneous resolution postpartum: a case report and review of the English literature. Obstet Gynecol Surv 1995; 50:404-10.

3. Vigneropn N, Barrier J, Degrelle G, Sockha R, Hector P. Lutéome virilisant de la grossesse. Rapport d'un cas et revue de la littérature. J Gynecol Obstet Biol Reprod (Paris) 1981; 10:147-53.
4. Garcia-Bunuel R, Berek JS, Woodruff JD. Luteomas of pregnancy. Obstet Gynecol 1975; 45:407-14.

5. Sternberg WH, Barclay DL. Luteoma of pregnancy. Am J Obstet Gynecol 1966; 95:165-84.

6. Clement PB. Tumor-like lesions of the ovary associated with pregnancy. Int $\mathrm{J}$ Gynecol Pathol 1993; 12:108-15.

7. Nagamani M, Gomez LG, Garza J. In vivo steroid studies in luteoma of pregnancy. Obstet Gynecol 1982; 59 Suppl:105S-11S.

8. Patterson R. Hirsutism in pregnancy. Obstet Gynecol 1985; 66:738-40.

9. Ben-Chetrit A, Greenblatt EM. Recurrent maternal virilization during pregnancy associated with polycystic ovarian syndrome: a case report and review of the literature. Hum Reprod 1995; 10:3057-60.

10.VanSlooten AJ, Rechner SF, Dodds WG. Recurrent maternal virilization during pregnancy caused by benign androgen-producing ovarian lesions. Am J Obstet Gynecol 1992; 167:1342-43.

11. Rodriguez M, Harrison TA, Nowacki MR, Saltzman AK. Luteoma of pregnancy presenting with massive ascites and markedly elevated CA 125. Obstet Gynecol 1999; 94:854.

12.Choi JR, Levine D, Finberg H. Luteoma of pregnancy: sonographic findings in two cases. J Ultrasound Med 2000; 19:877-81.

13.Piana S, Nogales FF, Corrado S, Cardinale L, Gusolfino D, Rivasi F. Pregnancy luteoma with granulosa cell proliferation: an unusual hyperplastic lesion arising in pregnancy and mimicking an ovarian neoplasia. Pathol Res Pract 1999; 195:859-63. 